\title{
Waiting for a consultation: Sorry, but the doctor cannot see you
}

\author{
Eldon A Shaffer MD FRCPC
}

$\mathrm{C}$ anadians are proud of their health care system. A key quality measure is access, reputed to be universal, yet a major obstacle to obtaining care (1). This problem includes wait times in finding and obtaining an appointment with a family physician and being referred for more highly specialized investigations when needed (2). Nevertheless, 20\% of Canadians experience adverse effects while awaiting general health care or a specialist's assessment, profoundly impacting their quality of life and carrying a fiscal cost in the workplace. Gastroenterology ranks with the top clinical areas in which family physicians and patients experience frustration while awaiting a consultation (3). In response, the Canadian Association of Gastroenterology has joined the Wait Time Alliance under the auspices of the Canadian Medical Association and developed consensus guidelines for medically acceptable wait times, stratified according to acuity into four categories: $24 \mathrm{~h}$, two weeks, two months and six months (4). Their most recent survey, however, suggests that wait times are actually worsening - now 30 days longer, generally, than in 2005 (5). For example, the targeted wait time for a patient with a high likelihood of experiencing severe inflammatory bowel disease is 14 days. The overall wait time is actually 126 days: 72 days before a consultation, followed by 44 days for a diagnostic endoscopy. In Calgary (Alberta), our central gastrointestinal triage servicing 23 gastroenterologists currently has wait times of two weeks, two months, 10 months and 16 months, for emergent, urgent, semi-urgent and nonurgent referrals, respectively (personal communication, Dr Kerri Novak, Division of Gastroenterology, University of Calgary). In Ontario, the median wait time to see a gastroenterologist approaches 100 days (6). From another perspective, primary care physicians vary in their threshold for initiating such referrals while many referrals do not provide sufficient information to make a valid medical decision about need or acuity. In fact, breakdowns and inefficiencies occur for all components of the specialty referral process across North America (7). The public has a growing awareness and expectation that consultations with specialists should be timely, but frequently are not.

What happens after a referral is declined or the fax machine is turned off? In the current issue of the Canadian Journal of Gastroenterology, de Boer et al (8) (pages 785-790) tracked the outcome of patients who were referred to their university division's central triage in Edmonton (Alberta) but were not accepted because their limited resources (inadequate number of gastroenterologists and endoscopy slots) precluded a timely evaluation. They assessed four referral diagnoses: abdominal pain, rectal bleeding, positive fecal occult blood tests and iron deficiency (unspecified was if all were anemic). In the 12 months following the original referral being declined, one-half (47.8\% [110 of 230 patients]) were seen by a gastroenterologist or surgeon, as captured through the Edmonton region data base from electronic medical records, and diagnostic imaging and pathology reports. In 9.1\% (21 of 230), a clinically relevant diagnosis was forthcoming. Five of these 12 had immediate clinical implications: Crohn disease, ulcerative colitis, celiac disease, colon cancer and small bowel obstruction from an incisional hernia. Overall, the rejected patients experienced a $15 \%$ increase in gastrointestinal $\mathrm{x}$-rays alone.
The authors are to be commended for initiating this important study of patient referrals that were declined. Limitations included the quality or completeness of the original referral (eg, not clearly identifying the acuity in those with significant disease, the celiac case without serology being performed), limited endoscopy documentation and no subsequent information for out-of-region patients. What is the 'natural' history of the other one-half (120 of 230) who were not captured by the imaging or pathology data base? One is left wondering what would have transpired had there not been an alternative group of consultants who were not part of their academic division yet were available in their region.

Interventions to improve the referral process should begin with involving consultants in educational activities, communicating with family physicians and disseminating clear guidelines with structured referral sheets (9). Preconsultation criteria for appropriate and adequate management should be available to referring physicians. Where feasible, there should be a central triage with reasonable guidelines that are transparent to all stakeholders. The decision making for access should not reside with administrative assistants reviewing faxes in consultants' offices. Ideally, the workforce should expand, increasing the number of gastroenterologists and available endoscopy slots. The latter might arise through screening endoscopies being performed outside the setting of high acuity, thus, lowering cost and yielding higher efficiencies. Alternatives to specialist referrals might come from family physicians with additional training and nurse clinicians under the supervision of gastroenterologists. A shifted outpatient model would envision specialists attending regularly scheduled clinics in the primary care setting, providing not only consultations but also an educationl opportunity (10). Finally, teleconferencing and outreach clinics are particularly attractive for rural settings.

What about patients who fall off the consultative pathway, either not accepted or waiting years? For nonurgent referrals, one strategy uses follow-up letters to better identify those still requiring a consultation and directing them to specialty clinics (11). An overarching challenge in triaging remains the ethics of rejecting consultations and the attendant medical-legal implications. Conversely, accepting consultations into an excessively long wait list carries its own set of accountabilities. Ignoring or disregarding referrals, however, merely shifts the burden of responsibility back onto primary care physicians.

Now for a reality check. Canada appears to have a relatively low number of gastroenterologists compared with other countries: 1.83 per 100,000 population in Canada versus 3.9 per 100,000 population in the United States (12). Burdened by rising health care costs, yet under constraints engendered by the current 'great recession', government agencies are unlikely to increase resources anytime soon. Access for performing endoscopy may not rise, limiting growth to mint additional gastroenterologists. More gastroenterologists performing more endoscopies, therefore, appears to be an unlikely solution. A further challenge to endoscopy access is the escalating number of procedures, many of which are not supported by contemporary guidelines (13). In addition, procedures such as screening colonoscopies, when once established, have an inherent growth

Division of Gastroenterology, University of Calgary, Calgary, Alberta

Correspondence: Dr Eldon A Shaffer, Division of Gastroenterology, University of Calgary, 3280 Hospital Drive, Calgary, Alberta T2N 426.

Telephone 403-220-8457, fax 403-592-5090, e-mail shaffer@ucalgary.ca

Received and accepted for publication October 1, 2012 
rate: $15 \%$ to $25 \%$ of such screens will detect adenomas. Colonoscopy surveillance, therefore, might increase $10 \%$ each year, doubling over the next decade (14).

The current state of the specialty-referral process is often flawed but contains substantial opportunities for innovation to facilitate access to gastroenterologists, reduce wait times and, ultimately, lower

\section{REFERENCES}

1. Carrière G, Sanmartin C. Waiting time for medical specialist consultations in Canada, 2007. Health Reports (Statistics Canada, Catalogue no. 82-003-XPE) 2010;21, no. 2, June

2. College of Family Medicine of Canada (The Primary Care Wait Time Partnership)....And still waiting: Exploring primary care wait times in Canada April. 2008 Discussion Paper. <www.cfpc.ca/ uploadedFiles/Resources/Resource_Items/PCWTP\%20 Discussion\%20Paper\%20v3.pdf> (Accessed April 2008).

3. Paterson WG, Barkun AN, Hopman WM, et al. Wait times for gastroenterology consultation in Canada: The patients' perspective. Can J Gastroenterol 2010;24:28-32.

4. Paterson WG, Depew WT, Paré P, et al; for the Canadian Association of Gastroenterology Wait Time Consensus Group. Canadian consensus on medically acceptable wait times for digestive health care. Can J Gastroenterol 2006;20:411-23.

5. Canadian Association of Gastroenterology Survey of Access to GastroEnterology (SAGE) News Release. Wait times for patients who need gastroenterology care are getting longer. June 19, 2012. <www.cag-acg.org/wta_sage_news_release_june2012.pdf> (Accessed September 2012).

6. Thind A, Stewart M, Manuel D, et al. What are the wait times to see a specialist? An analysis of 26,942 referrals in Southwest Ontario. Health Care Policy 2012;8:80-91.

7. Mehrotra A, Forrest CB, Lin CY. Dropping the baton: Specialty referrals in the United States. The Millbrook Quarterly 2011;89:39-68. patient mortality and morbidity while minimizing personal and fiscal stress. A better working approach with family physicians and administrative leaders is essential. Given our limited resources, gastroenterologists must prioritize and ensure that every procedure performed is appropriate. Let us seize this opportunity to increase capacity, reduce unnecessary demand and so improve access. Wait no longer.

8. deBoer E, Pincock D, van Zanten SV. The 'natural history' of declined outpatient gastroenterology referrals. Can J Gastroenterol 2012;26:785-90.

9. Akbari A, Mayhew A, Al-Alawi MA, et al. Interventions to improve outpatient referrals from primary care to secondary care. Cochrane Database Syst Rev 2008;(4):CD005471. Updated 2011;1:1-58.

10. Frost DW, Toubassi D, Detsky AS. Rethinking the consultation process: Optimizing collaboration between primary care physicians and specialists. Can Fam Physician 2012;58:825-8.

11. Stainkey LA, Seidl IA, Johnson AJ, et al. The challenge of long waiting lists: How we implemented a GP referral system for nonurgent specialist' appointments at an Australian public hospital. BMC Health Serv Res 2010,10:303 <www.biomedcentral. com/1472-6963/10/303> (Accessed November 2010).

12. Moayyedi P, Tepper J, Hilsden R, Rabeneck L. International comparisons of manpower in gastroenterology. Am J Gastroenterol 2007;102:478-81.

13. Armstrong D, Khanna S. Gastrointestinal endoscopy in Canada: National trends from 2004-5 to 2008-9. Can J Gastroenterol 2012;Suppl A:97A.

14. Leddin D. Surveillance colonoscopy in average-risk cancer screening programs will double colonoscopy requirements in 10 years a mathematical model of program growth Can J Gastroenterol 2012;(Suppl A):74A. 


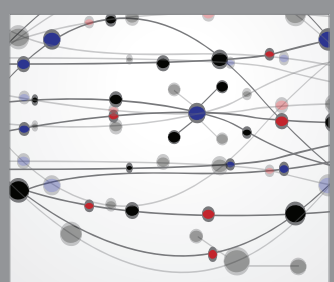

The Scientific World Journal
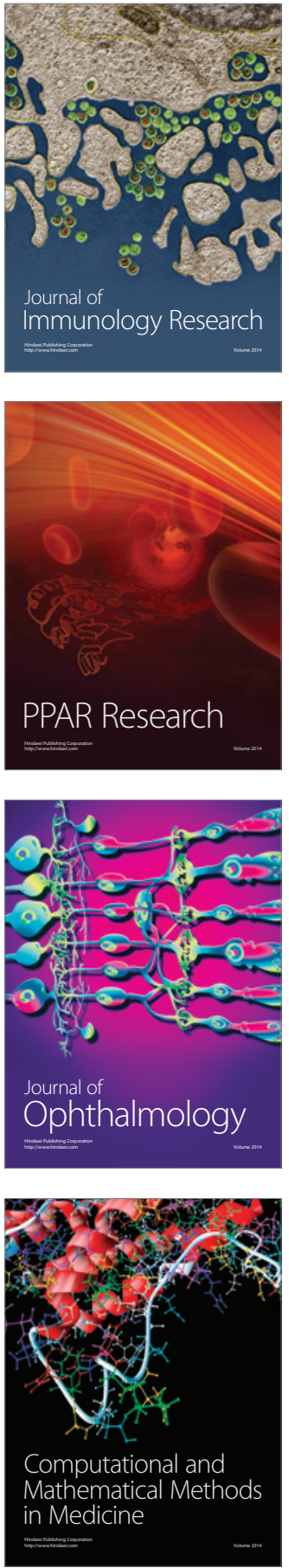

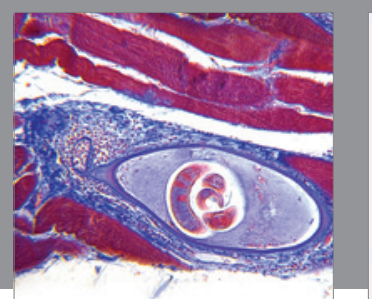

Gastroenterology Research and Practice

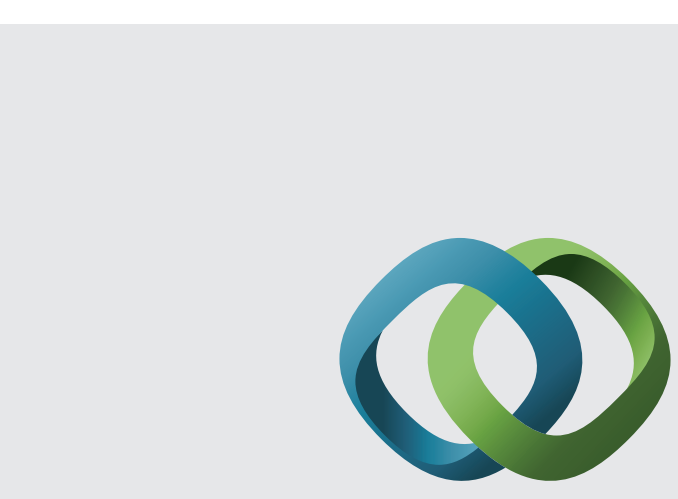

\section{Hindawi}

Submit your manuscripts at

http://www.hindawi.com
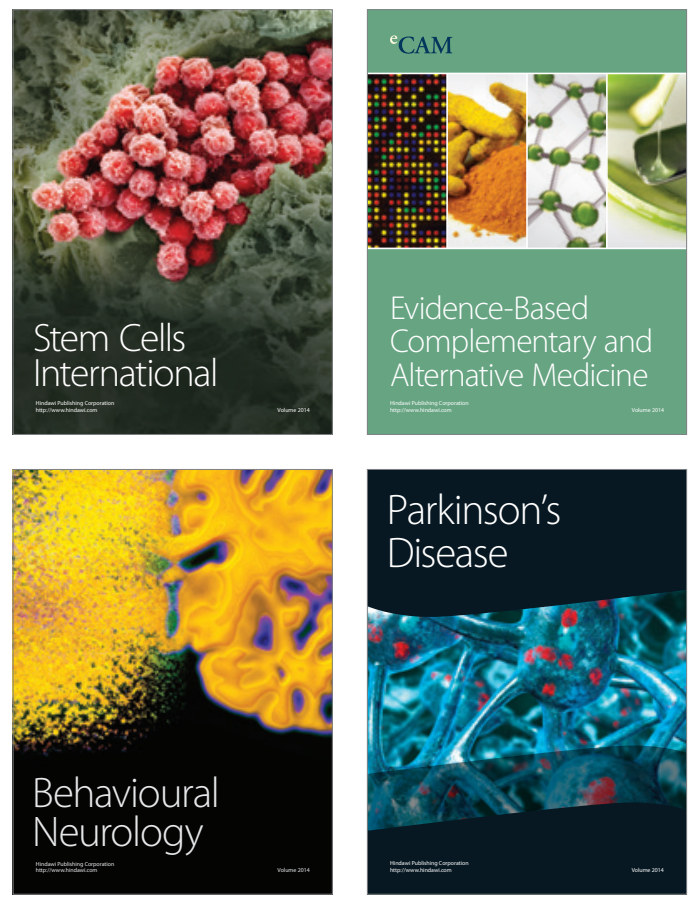
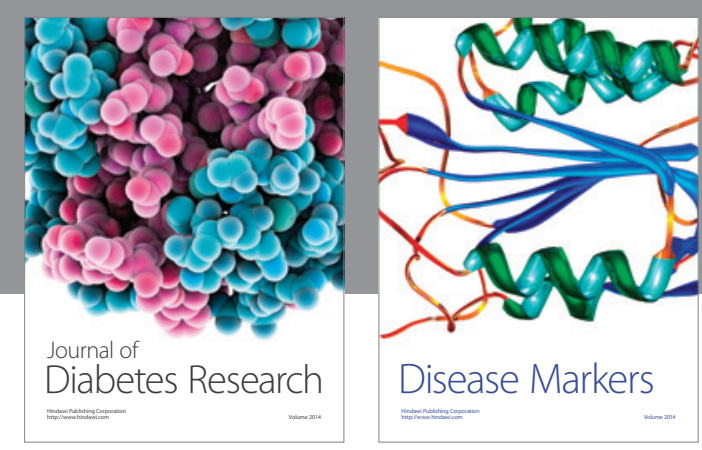

Disease Markers
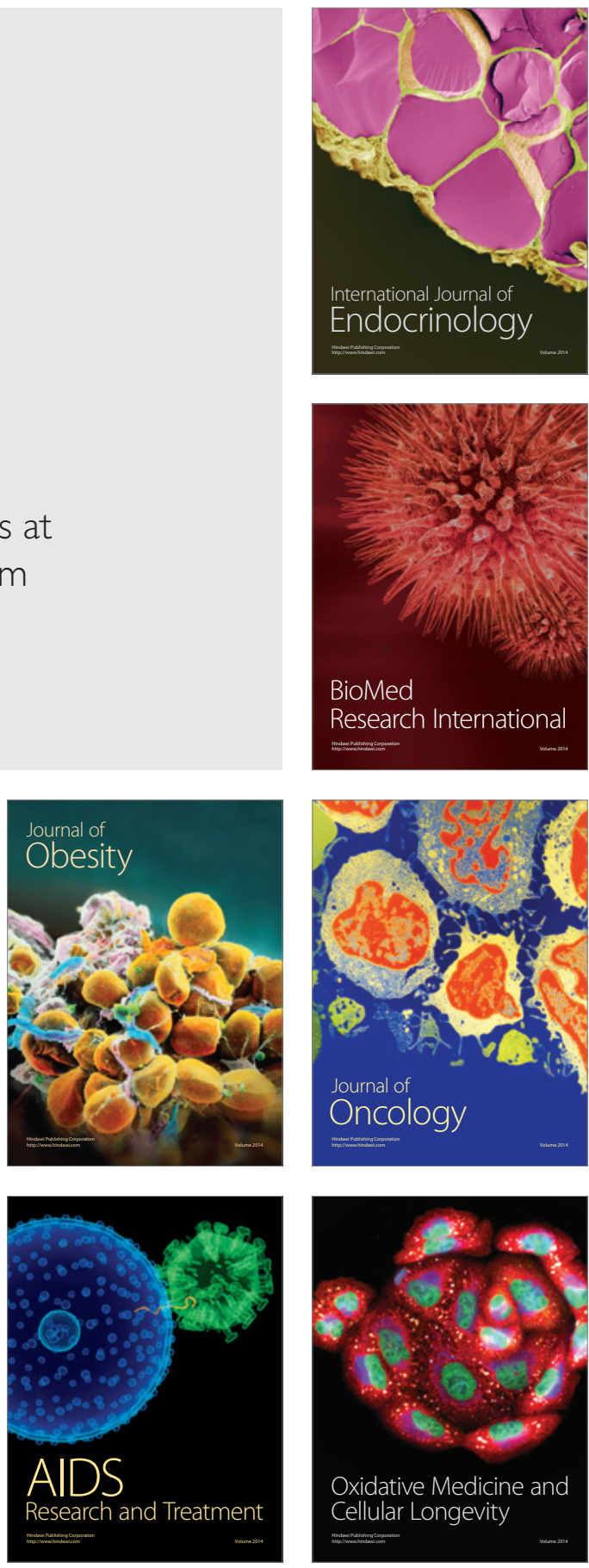